\title{
A Framework for Conducting Critical Dialectical Pluralist Focus Group Discussions Using Mixed Research Techniques
}

\author{
Anthony J. Onwuegbuzie (Corresponding author) \\ Department of Educational Leadership and Counseling, Box 2119 \\ Sam Houston State University, Huntsville, Texas 77341-2119, USA
}

Tel: 1-936-294-4509Ｅ-mail: tonyonwuegbuzie@aol.com

\author{
Rebecca K. Frels \\ Department of Counseling and Special Populations \\ Lamar University, 223 Education Building, Beaumont, Texas 77710, USA \\ E-mail: rebecca.frels@gmail.com
}

Received: October 5, 2015 Accepted: December 7, 2015

Published: December 15, 2015

doi:10.5296/jei.v1i2.8662ＵRL: http://dx.doi.org/10.5296/jei.v1i2.8662

\begin{abstract}
Although focus group discussions (FGDs) represent a popular data collection tool for researchers, they contain an extremely serious flaw: FGD researchers have ultimate power over all decisions made at every stage of the research process - from the conceptualization of the research, to the planning of the research study, to the implementation of the research study, to the dissemination of FGD findings. Yet, exercising 100\% control over all decisions in FGD research can be detrimental for some participants, especially for under-represented, underserved, and marginalized populations. Thus, in this article, we introduce a new type of participant-directed FGD, which we call a critical dialectical pluralist FGD, wherein participants are maximally empowered to make decisions at every stage of the mixed research process. We outline the stages of critical dialectical pluralist FGDs and provide a real-life example of this approach.
\end{abstract}

Keywords: Critical dialectical pluralism, Critical dialectical pluralist, Focus group 
discussions, Social justice research

\section{Introduction}

The use of focus group discussions (FGDs) in empirical research offers several advantages. These advantages include the following: (a) FGDs represent an efficient (i.e., economical and relatively fast) way of obtaining information from several individuals because participants are interviewed in groups rather than on an individual basis (Krueger \& Casey, 2000); (b) FGDs have the potential to increase the sample size in a qualitative research study (Krueger, 2000); (c) FGDs allow researchers to evaluate critically three levels of saturation: within-focus group saturation (i.e., degree to which data from any single FGD reached saturation), across-focus group saturation (i.e., degree to which saturation occurred across all the FGDs conducted on all the participants), and across-participant saturation (i.e., degree to which saturation occurred across all the FGDs conducted on a single participant) - which, if evidence was obtained for all three levels of saturation, would yield meta-saturation (Nelson, Onwuegbuzie, Wines, \& Frels, 2013); (d) FGDs provide a socially oriented method of collecting data within social contexts (Krueger, 2000); (e) FGDs yield information from the interaction that occurs among participants (Morgan, 1988); (f) FGDs have the potential to motivate a greater degree of spontaneity in participants' responses compared with individual interviews (Butler, 1996); (g) FGDs can provide a safe venue for participants to respond to interview questions (Vaughn, Schumm, \& Sinagub, 1996); (h) FGDs can evoke a sense of group membership and cohesiveness that empowers participants (Peters, 1993); and (i) FGDs provide an opportunity for participants to deconstruct personal problems and to discuss potential solutions (Duggleby, 2005).

As do virtually all focus group methodologists, Morgan (2008) defined focus groups as "a form of qualitative interviewing" (p. 352). Indeed, it was not until very recently that Onwuegbuzie, Dickinson, Leech, and Zoran (2010) conceptualized focus groups as optimally involving the use of mixed research techniques because both qualitative and quantitative data can be collected, analyzed, and interpreted from focus groups. Consequently, Onwuegbuzie et al. (2010) provided a mixed research framework for collecting, analyzing, and interpreting data collected from FGDs. Specifically, their mixed research-based FGD framework involved the collection and analysis of three forms of FGD data: individual data, group data, and group interaction data. A key component of their mixed research-based FGD framework was what they called a micro-interlocutor analysis. In addition to traditional qualitative (i.e., text) data, micro-interlocutor analysis involves the collection and analysis of qualitative and quantitative data such as which participant responds to which questions, the number of participants who responded to each question, and the order in which the participants respond, as well as the nonverbal communication (e.g., proxemics, chronemics; Onwuegbuzie \& Byers, 2014) used.

\section{Researcher-Directed Nature of FGDs}

Although FGDs represent a popular data collection tool used by many researchers, it contains an extremely serious flaw. Specifically, FGDs are designed to be totally in the control of the researcher(s). That is, FGD researchers have ultimate power over all decisions made at every stage of the research process - from the conceptualization of the research, to the development 
of research question(s) for which FGDs are needed, to the design of the FGDs, to the implementation of the FGDs, to the collection of data from the FGDs, to the analysis and interpretation of data collected from the FGDs, to the validation of data and interpretations emanating from the FGDs, to the meaning making of interpretations emanating from the FGDs, to the dissemination of findings from the FGDs. In particular, until now, FGD researchers have exercised control over all decisions regarding the elements of the voice from FGDs that are included and excluded, as well as the extent and veracity with which each FGD participant's story is told. Yet, exercising 100\% control over all decisions in FGD research can be detrimental for some participants, especially for under-represented, underserved, marginalized, and oppressed individuals and groups. Unfortunately, to date, this flaw in FGD methodology has not been identified in any research methodology textbook in general and FGD textbook in particular.

What are also needed are participant-directed FGDs. Thus, the purpose of this article is to introduce a new type of FGD, which we call a critical dialectical pluralist focus group discussion, or, more simply, a critical dialectical pluralist FGD. The major feature of critical dialectical pluralist FGDs is that participants are maximally empowered to make decisions at every stage of the research process - whether the study represents qualitative research or mixed research.

\section{Theoretical Framework}

Critical dialectical pluralism is centered on the assumption that social injustices permeate all levels of society. According to Onwuegbuzie and Frels (2013) - its developers - critical dialectical pluralists aim to conduct research wherein an egalitarian society is promoted and sustained for the purpose of advancing both universalistic theoretical knowledge and local practical knowledge, and to conduct culturally progressive research. Therefore, critical dialectical pluralists privilege research philosophies that promote social justice, including: (a) transformative-emancipatory (Mertens, 2003, 2007, 2010), critical theory (Morrow \& Brown, 1994), critical race theory (Delgado \& Stefancic, 2012), feminist theory (Hesse-Biber, 2010), critical ethnography (Thomas, 1993), critical quantitative research (Baez, 2007; Stage, 2007; Teranishi, 2007), and critical integrated research and evaluation in peace research (Onwuegbuzie \& Tashakkori, 2015). Critical dialectical pluralist researchers strive to avoid conducting research that yields any form of cultural deficit model being advanced; rather, they incorporate the social and cultural capital that prevails among under-represented, marginalized, and oppressed populations, such as their resiliency, often leading to the conduct of resiliency-based research.

Critical dialectical pluralism is distinct from other transformation-based research philosophies that are geared toward some form of social justice (e.g., transformative-emancipatory, critical theory, critical race theory, feminist theory, critical ethnography, critical quantitative research) by empowering participants to make research-based decisions at as many stages of the research process as possible. This is accomplished by the critical dialectical pluralist researcher adopting a mixed research-facilitator role that allows participants to serve as participant-researchers who 
meta-ethically co-construct knowledge using mixed research techniques and then disseminate the findings themselves, or with the research-facilitator(s), in a format of their choice. This transfer of research power from mixed researcher to participants within the ensuing mixed research-facilitator/researcher team, in turn, transforms the research from representing an etic perspective or even an emic perspective to an emtic perspective (i.e., "representing the place where emic and etic viewpoints are maximally interactive"; Onwuegbuzie, 2012, p. 205). As noted by Onwuegbuzie and Frels (2013),

Importantly, participants have a co-equal say in what phenomenon should be studied; how research should be conducted to study this phenomenon; which methods should be used; which findings are valid, acceptable, and meaningful; how the findings are to be disseminated and utilized; and how the consequences of such decisions and actions are to be assessed. Indeed, the participant(s) is responsible for deciding what text remains in the final report, and, as noted previously, the participant(s) performs the findings alone or in partnership with the research-facilitator. In contrast, the research-facilitator assumes the role of democratic facilitator and consciousness raiser, or cultural broker between the participant-researcher(s) and entities that have power over them. (p. 15)

Critical dialectical pluralism involves the adoption of a pluralist ontological stance (hence the word pluralism); relies on a dialogical, hermeneutical, and, above all, a dialectical approach to understanding phenomena (hence the word dialectical); and promotes and sustains social justice, not only within the social milieu, but also within the research setting (hence the word critical).

Although critical dialectical pluralism has been in formal existence since 2013, already it has started to become popularized. For example, critical dialectical pluralism is serving as the driving force for the upcoming Mixed Methods Regional Conference focusing on patient-centered mixed methods research, entitled, Patient Engagement in Biomedical and Health Services Research: A Pragmatic Mixed Methods Approach, which will take place in San Antonio, TX on August 3-4, 2015. According to the call for papers, "This 2015 Regional conference is a research design and methodology conference where methodological and technical issues of major importance in the field of health services research will be addressed." Interestingly, according to the conference organizers:

The assumptive base of the mixed methods paradigm entitled critical dialectical pluralism (Onwuegbuzie \& Frels, 2013) is that social injustices prevail in every society and that our major challenge in health services research today is how to adequately address the social justice issue of health disparities. We maintain that the critical dialectical pluralist researcher promotes research that "focuses directly on the lives, experiences, and perceptions of underserved persons or groups and promotes research examining the relationship between societal structures and ideological mental models that impede a person or group from identifying, problematizing, confronting and addressing unjust socio-cultural systems". This paradigm is compatible with the principles and values of community-engaged or patient-engaged research approaches (CEnR). 


\section{Mapping Critical Dialectical Pluralism onto the FGD Process}

Critical dialectical pluralism can be applied to focus groups to yield what we call critical dialectical pluralism FGDs. As noted previously, this form of FGD involves the researcher(s) maximally empowering participants to make decisions throughout the qualitative research or mixed research process. We conceptualize critical dialectical pluralism FGDs as representing the following 10 stages: (a) Stage 1: the researcher forming the FGD groups; (b) Stage 2: scheduling the pre-FGD sessions; (c) Stage 3: participant-researchers co-constructing research questions during the pre-FGD sessions; (d) Stage 4: participant-researchers co-constructing the FGD interview question(s) during the pre-FGD sessions; (e) Stage 5: participant-researchers selecting the moderator and assistant moderator and conducting the first FGD sessions; (f) Stage 6: participant-researchers conducting the first FGD session; (g) Stage 7: participant-researchers transcribing and distributing the transcripts from the first FGD session; (h) Stage 8: participant-researchers conducting the second FGD session to member-checking the transcripts; (i) Stage 9: participant-researchers conducting the third FGD session to co-analyze the FGD data; and (j) Stage 10: participant-researchers deciding how they will document and disseminate the FGD findings and interpretations. Each of these stages is discussed briefly in the following sections.

\subsection{Stage 1: Form the FGD Groups}

Once the researcher has identified a research problem, the first step is for the researcher to form the FGDs. As specified in the literature, FGDs should contain between six and 12 participants (Johnson \& Christensen, 2013; Onwuegbuzie, Dickinson, Leech, \& Zoran, 2009, 2011; Onwuegbuzie et al., 2010), or between three (Morgan, 1997) and four (Krueger, 1994) participants that yield "mini-focus groups" (Krueger, 1994, p. 17) or what we term mini-FGDs, wherein participants have specialized knowledge and/or experiences. Assuming that sufficient time is given for each focus group session-typically, between 1 and 2 hours - forming FCDs containing between six and 12 participants or mini FGDs containing between three and four participants should yield FGD sessions wherein everyone has the opportunity to have their voice heard and, at the same time, increases the opportunity for within-focus group saturation to occur (Nelson et al., 2013). Further, three to six FGDs should be formed (Krueger, 1994; Morgan, 1997) so that data saturation (i.e., which occurs when information is repeated so often that the researcher can anticipate it and wherein collecting more data appears to yield no additional interpretive worth; Sandelowski, 2008; Saumure \& Given, 2008) and/or theoretical saturation (i.e., which occurs when the researcher can assume that his/her emergent theory has been developed adequately to fit any future data collected; Sandelowski, 2008) could occur. Further, this number of FGDs allows across-focus group saturation and across-participant saturation to be reached (Nelson et al., 2013)_yielding meta-saturation. As such, including an appropriate number of participants in each FGD and having an adequate number of FGDs increase the likelihood that meta-saturation would occur (Nelson et al., 2013).

These FGDs groups can be formed at random, using one of the five random sampling schemes; or purposively, using one of the 19 purposive sampling schemes that Onwuegbuzie 
and Collins (2007) identified. These 24 sampling schemes that can be used to select participants for FGDs are presented in Appendix 1. Alternatively, the participants themselves can form these groups. Alternatively still, the FGDs might form themselves naturally because they represent intact groups.

\subsection{Stage 2: Schedule the Pre-FGD Sessions}

Once participants for FGD groups have been selected, the next stage is to schedule and to hold the pre-FGD sessions. The most efficient way is to arrange for all FGD groups to have their pre-FGD session at the same time and location. This is because the researcher can explain the FGD protocol at one time. Also, we have found that hosting all pre-FGD groups simultaneously is extremely synergistic because the different FGD groups are able to feed off each other. However, in many instances, hosting all pre-FGD sessions simultaneously is difficult to accomplish because it means finding a common time to meet for a minimum of 18 participants (i.e., the minimum of 6 participants per FGD $\times$ the minimum of 3 FGDs) for FGDs or nine participants (i.e., the minimum of 3 participants per FGD $x$ the minimum of 3 FGDs) for mini-FGDs. In these cases, the researcher would schedule each pre-FGD session at a time and location that is convenient for all FGD participants. Once scheduled, the pre-FGD meeting(s) should be held.

\subsection{Stage 3: Co-Construct Research Questions}

At the pre-FGD meeting - that involves one, some, or all the FGD groups-the research-facilitator should begin by introducing himself/herself and all FGD participants to each other. It might be beneficial for the FGD participants to stay connected outside the FGD sessions. For example, the FGD participants could connect with each other via Facebook. After the introductions have been made, the next task is for the research-facilitator to explain the FGD protocol (e.g., outline the 10 stages of the process). After providing this explanation, the FGD participants should be ready for action. This first action should take the form of co-developing the research question(s). Indubitably the biggest myth that is perpetuated in nearly every research methodology textbook is that researchers not only should be the ones to develop research questions but also they should do so alone. Simply put, researchers are considered as the experts when it comes to developing research questions - in what Onwuegbuzie and Frels (2013) refer to as representing a "research-based medical model" (p. 17), wherein the researcher acts as the expert and participant serves as the passive person who is studied. Yet, it is often not the case that the researcher is the (only) person who knows the most appropriate research question(s) to pose. In fact, in many situations, it is the participant(s) who understands fully what the research problem is because the research problem reflects the reality of the participant(s) and not that of the researcher-especially when the researcher(s) assumes an etic (i.e., outsider) perspective-which is often the case.

Consistent with the tenets of critical dialectical pluralism, critical dialectical pluralist FGD researchers operate under the assumption that "just as patients often are more knowledgeable about their own bodies than are physicians, so too are research participants often more knowledgeable about their own study setting than are the researchers" (Onwuegbuzie \& Frels, 2013, p. 14). As such, given the research problem of interest to the researcher, an important 
first step of critical dialectical pluralism FGD researchers is to create an environment where the participants co-construct the research question(s) with the researcher. In either case, the participants' role is transformed to the role of participant-researchers, while the researcher, in turn, changes her/his role from the researcher to a research-facilitator. Here, the research-facilitator's primary role is to make sure that the co-constructed research questions are consistent with the best practices for developing quantitative and qualitative research questions (cf. Onwuegbuzie \& Leech, 2006), as well as mixed research questions (cf. Onwuegbuzie \& Leech, 2006; Plano-Clark \& Badiee, 2010). For example, with regard to quantitative research questions, Onwuegbuzie and Leech (2006) advised the following:

Good quantitative questions should identify the population and dependent variable(s), whether they represent descriptive, comparative, or relationship research questions. If they represent comparative or relationship research questions, then the independent variable(s) also should be identifiable. Researchers should avoid starting a quantitative research question with the words, "Do," "Does," "Is," or "Are" because they motivate "yes/no" responses, which, in turn, place undue emphasis on null hypothesis significance tests, possibly to the exclusion of indices of practical significance. (p. 482)

With respect to mixed research questions, as identified by Plano Clark and Badiee (2010), the following types of research questions can be constructed: separate research questions (i.e., representing one or more quantitative research questions coupled with one or more qualitative research questions), general overarching mixed methods research questions (i.e., representing broad research questions that are answered via both quantitative and qualitative research approaches), hybrid mixed methods issue research questions (i.e., representing one research question that contains two distinct parts such that a quantitative research approach is used to address one part and a qualitative research approach is used to address the other part), mixed methods procedural/mixing research questions (i.e., representing narrow research questions that shape the mixing or combining of the qualitative and quantitative strands of the study), combination research questions (i.e., representing at least one mixed research question mixed or combined with separate quantitative and qualitative research questions), independent research questions (i.e., representing two or more research questions that are related in some manner, with each research question not depending on the results of the other question[s]), dependent research questions (i.e., representing research questions that depend on the results stemming from addressing another question), predetermined research questions (i.e., representing research questions that are based on literature, practice, personal tendencies, and/or disciplinary considerations that are posed at the beginning of the study), and emergent research questions (i.e., representing new or modified research questions that emerge during the design, data collection, data analysis, or data interpretation phase). Optimally, if all the pre-FGD sessions can be held at the same time and place, then the research question development process can occur in one session. However, in the many situations in which one or more pre-FGD sessions are held separately, then the first draft of the research question(s) will be developed in the first pre-FGD session that is held, and then in the subsequent pre-FGD sessions, this draft will be modified (as deemed necessary by these pre-FGD participants) and finalized. Whatever final research question(s) that emerges from the 
pre-FGD session(s), it is important that each question reflects input from every researcher-participant across all pre-FGD sessions.

\subsection{Stage 4: Co-Construct FGD Interview Questions}

In a similar vein, research methodology textbook authors perpetuate the myth that researchers not only should be the ones to develop the interview questions but also they should do so alone. Yet, in many situations, it is the participant(s) who can determine what the most pertinent interview questions are because of being in the best position to identify the questions that will generate the richest data related to the co-constructed research question(s) (cf. Stage 2). Thus, once the research question(s) has been co-constructed, within the same pre-FGD sessions, the next step is for all the FGD participants to co-construct the interview question(s).

In selecting the interview questions, the research-facilitator should ensure that FGD participants are mindful of the ratio of the number of interview questions to the size of the FGD group to the length of the FGD (i.e., question-size-time ratio). In particular, holding the number of FGD participants constant, the more time allocated to the FGD session, the more interview questions can be asked. Further, holding the time allocated to the FGD session constant, the smaller the FGD group, the more interview questions can be asked. Finally, holding the number of interview questions constant, the more time allocated to the FGD session, the bigger the FGD group can be. The research-facilitator could use a few simple mathematical calculations to help determine an appropriate number of interview questions. For example, if the FGD participants were available for a 1-hour FGD session, and there were six members of the FGD team, then, on average, you can expect each FGD participant to be able to talk for a total of 10 minutes. Therefore, for a given a research topic and research questions, the question that the research-facilitator should ask the FGD participants as they co-construct their interview questions is how many interview questions can yield rich responses from an individual within a 10-minute time frame bearing in mind, for instance, that U.S. adults who are speaking with no long pauses, typically utter between 150 and 170 words per minute (cf. Robb, Maclagan, \& Chen, 2004)? As an example, five interview questions would mean that, on average, each person in a six-person FGD that lasted for 1 hour would have 2 minutes to respond to each question. And by the research-facilitator providing this kind of information to the FGD participants would help them decide the maximum number of interview questions to co-construct.

\subsection{Stage 5: Selecting the Moderator and Assistant Moderator and Conducting the First FGD Sessions}

Once the interview questions have been co-constructed, within the same pre-FGD sessions, the next stage is for each FGD to select both the moderator and assistant moderator. As recommended by Onwuegbuzie et al. $(2009,2010,2011)$, moderators should never mediate FGD sessions alone; rather, they should work alongside assistant moderators. In the context of FGDs, the moderator - who will represent one of the FGD participant-researchers - is responsible for facilitating the FGD session, motivating and prompting members to speak, ensuring that overly talkative members allow other members to talk, and encouraging all the 
members to contribute to the discussion. Additionally, the FGD moderator is responsible for taking notes (e.g., handwritten, via a computer or mobile device) and for identifying responses from FGD members that inform potential emergent questions to ask. One major difference between critical dialectical pluralist FGD moderators and moderators of traditional focus groups is that whereas the latter only poses the questions, the former also plays a role in answering the questions, although these moderators need to monitor their own behaviors to ensure that they do not dominate the discussions. Contrastingly, the assistant moderators have several responsibilities that include recording the session (i.e., whether via audio- or videotape) with the permission of every FGD member, taking comprehensive notes, managing the logistics and environmental conditions, addressing any other issues that prevent the FGD session from running smoothly (e.g., dealing with technology issues), and providing verification of data.

In addition to recording verbal data during the first FGD session, the moderator and assistant moderator also should collect nonverbal communication data. Disturbingly, Denham and Onwuegbuzie (2013) documented that the overwhelming majority of focus group sessions (i.e., 72.2\%) do not involve the collection, analysis, and interpretation of nonverbal communication data that are generated from focus groups. In particular, we suggest that FGD moderators and moderators utilize the framework for collecting, analyzing, and interpreting nonverbal communication data that Onwuegbuzie et al. (2010) refer to as a micro-interlocutor analysis. As illustrated by Onwuegbuzie and Hitchcock (2015), micro-interlocutor analysis is a mixed research-based framework for collecting, analyzing, and interpreting nonverbal communication data in FGDs, transforming the analysis of FGD data from a qualitative analysis to a mixed analysis (cf. Onwuegbuzie \& Combs, 2010), which, in turn, adds more rigor to FGD research. With regard to quantitative data, nonverbal communication data that can yield important insights include the number of participants who responded to each question, the order in which the participants respond to each question, and the length of response (e.g., time spent responding, number of words spoken). Additionally, micro-interlocutor analysis involves researchers identifying the number of FGD participants who contributed to the feeling of consensus underlying each theme that is obtained from the FGD data, the number of FGD members who provided a dissenting view, the number of FGD participants who did not express any view at all, the number of FGD members who provided substantive statements or examples that support the consensus view, and the number of FGD participants who provided substantive statements or stories that indicate a dissenting view (Onwuegbuzie \& Hitchcock, 2015).

Micro-interlocutor analysis includes comparing subgroups within an FGD (e.g., male vs. female members) relative to the members' interaction patterns, such as which subgroup member, if any, tended to speak first in response to a question, and which subgroup members spoke the most. Importantly, collecting and analyzing data about dissenting FGD participants helps analysts to ascertain the degree to which meta-saturation (i.e., within-focus group saturation, across-focus group saturation, and across-participant saturation) took place.

Ideally, the first FGD session would take place in the same session as the pre-FGD meeting. However, if there is insufficient time for this to occur, then a second FGD meeting should be 
set up to hold the first FGD session. Again, it would be most efficient if all the first FGD sessions took place at the same time and location. Otherwise, each FGD session would take place individually.

\subsection{Stage 6: Conduct the First FGD Session}

Once the interview questions have been co-constructed, the moderator and assistant moderator selected, and the first FGD session scheduled, the next stage is for the research-facilitator to arrange for the FGD session to take place at the allotted time. Whenever possible, these sessions should be audio- or video-recorded. And because, in the critical dialectical pluralist tradition, the participant-researchers own their own data, securing permission from all FGD participants should be a formality. Depending on the dynamics of the FGD team, the research-facilitator either should stay in the background or foreground as the FGD session takes place. Regardless of how research-facilitators are positioned within the FGD session, they should observe the FGD session carefully and take a comprehensive a set of notes as possible either during the session (i.e., optimal time) or immediately after the session has ended and the FGD participants have dispersed. At the end of the FGD session, the participants should schedule the next FGD session.

\subsection{Stage 7: Transcribe and Distribute the Transcripts from the First FGD Session}

Once the FGD session has been completed, the interview responses need to be transcribed. If the FGD participants prefer, they could transcribe the interview responses themselves (i.e., optimal arrangement). Otherwise, the research-facilitators would arrange for the transcription to take place either themselves (i.e., next most optimal arrangement) or by outsourcing this task to someone else (e.g., paying an experienced transcriber). Whoever is responsible for transcribing the interview responses, it is essential that the transcribing is undertaken as soon as possible after the FGD session ends. And the transcription should not only include the recording of verbal data but also nonverbal communication data (Onwuegbuzie \& Byers, 2014).

\subsection{Stage 8: Conduct the Second FGD Session to Member-Check the Transcripts}

After the interview responses have been transcribed, the transcription should be distributed to all FGD participants either at the second FGD session or, ideally, before this session (e.g., via email or Facebook), to enable them to read carefully the transcript before this session. In any case, during the second FGD session - led by the same moderator and assistant moderator, or a different moderator team, if the FGD participants decided to rotate this moderator team-each participant should delineate to all other FGG participants any deletions, corrections, or expansions to the transcripts that are needed. The goal of this member checking should be to assess both accuracy and adequacy (i.e., representativeness) of the verbal and nonverbal responses (Manning, 1997), thereby increasing both descriptive validity (i.e., the factual accuracy and adequacy of the account as documented by the transcriber; Maxwell, 1992) and interpretive validity (i.e., the extent to which the subsequent interpretations stemming from the FGD data represent an understanding of the perspective of the FGD participants under study and the meanings attached to their words and actions; 
Maxwell, 1992). This second FGD session not only provides FGD participant-researchers the opportunity to confirm earlier responses made by everyone but also provides an opportunity for ensuring that every FGD group member's voice has been represented maximally (i.e., within-focus group saturation) - further increasing both descriptive validity and interpretive validity.

According to Cho and Trent (2006), transactional validity is "an interactive process between the researcher, the researched, and the collected data that is aimed at achieving a relatively higher level of accuracy and consensus by means of revisiting facts, feelings, experiences, and values or beliefs collected and interpreted" (p. 321). In contrast, transformative validity is "a progressive, emancipatory process leading toward social change that is to be achieved by the research endeavor itself" (Cho \& Trent, 2006, pp. 321-322). Thus, another goal of the member checking of the FGD data is to establish both transactional validity and transformative validity. An extremely powerful aspect of this member checking stage is that all modifications to the FGD transcript can be made by the moderator in front of all FGD participants.

After the member checking stage has been completed - assuming that this stage did not take too long, at the same FGD session, the research-facilitators next would show the FGD participants how to analyze their own data and to identify themes, meta-themes, and subthemes. The qualitative data analysis approach(es) shown would depend, at least in part, on the education level of the FGD participants. Indeed, the qualitative data analysis approaches can range from the most basic approaches such as word count (DeRocher, James, Miron, Patten, \& Pratt, 1973) and classical constant analysis (Berelson, 1952); to intermediate approaches such as constant comparison analysis (Glaser, 1965); to advanced approaches such as qualitative comparative analysis (Ragin, 1987, 1989, 1994, 2008) and interpretive phenomenological analysis (Smith, 1996a, 1996b). For example, the research-facilitator could refer the FGD participants to articles that provide step-by-step guides to qualitative data analysis (e.g., Leech \& Onwuegbuzie, 2007).

\subsection{Stage 9: Conduct the Third FGD Session to Co-Analyze the FGD Data}

Once the FGD participants have agreed on what qualitative data analysis approach(es) to use, the next phase is for them to co-analyze the FGD data. This would occur during the third FGD session, led, again, by the same moderator and assistant moderator, or a different moderator team, if the FGD participants decided to rotate this team. As the themes are identified, the assistant moderator would record them in a reader-friendly way as possible such as via a Microsoft PowerPoint presentation, which would be presented back to all FGD participants at the end of the session for feedback and recommended modifications. It is very possible that more than one FGD session will be needed to complete the data analysis and data interpretation. These additional sessions can be conducted face-to-face, or for those FGD participants with Internet access, via videoconferencing software programs that are free to use such as Skype, ooVoo, and Google Hangouts. 
4.10 Stage 10: Decide How the FGD Findings and Interpretations Will be Documented and Disseminated

Upon completion of the analysis and interpretations, in the first post-analysis FGD session, consistent with the tenets of critical dialectical pluralism, the FGD participants would decide how the findings and interpretations will be documented and disseminated. Indeed, the FGD participants can select from several avenues for disseminating their findings such as completing one or more articles that are submitted to a journal for consideration for publication, writing a book chapter, writing a book, writing a newspaper article, presenting their findings at a conference, and/or creating a YouTube video. For academic outlets in particular, the research-facilitator can play an important role here in helping them achieve this goal. Whatever outlet(s) is chosen, the important aspect is this stage is that the FGD participants are empowered to decide which avenues to pursue. Alongside this outlet decision, the FGD participant-researchers would outline a cooperative action plan for fulfilling these dissemination goals. The final part of the critical dialectical pluralist FGD process would be to realize this action plan.

Throughout the FGD stages, the participant-researchers undergo a series of debriefing interviews that are conducted by the research-facilitator to assist them in reflecting on the FGD process and product (Collins, Onwuegbuzie, Johnson, \& Frels, 2013). The goal of these debriefing interviews also is to help FGD participant researchers to arrive at solutions for any problems that arise (Collins, Onwuegbuzie, Johnson, \& Frels, 2013).

\section{Conclusions}

In the previous sections, we have outlined our 10-stage critical dialectical pluralist FGD process. Over the years, we have been very fortunate to have been invited to several nations in Africa (e.g., Kenya, Uganda, Tanzania) to deliver intensive (i.e., 1-week and 2-week) courses on research methodology (i.e., quantitative, qualitative, and mixed methodology) to university professors from 21 African countries in Eastern and Southern Africa who teach research methodology courses/workshops to Ph.D. students and supervise doctoral dissertations. Specifically, we were invited by members of the Organization for Social Science Research in Eastern and Southern Africa (OSSREA) - specifically, Dr. Paulos Chanie, Director of Research and Dr. Melese Getu, Research Associate. According to its website (http://www.ossrea.net/), OSSREA is

a non-governmental and non-profit research network that was founded in 1980 in the town of Nazareth, Ethiopia, by a group of social scientists from Eastern Africa. Its constituency is based on membership drawn from social scientists and institutions engaged in teaching and/or research in the social sciences in Eastern and Southern Africa. Currently, there are 21 member countries in the region where OSSREA has National Chapters and Liaison Offices.

We consider teaching these courses/workshops to be the most uplifting part of our profession. Indeed, every time we teach these courses/workshops, we end up learning a lot from our participants, resulting in a co-construction of knowledge, which is a very effective way to 
teach and to learn. While teaching these courses/workshops, we have had the opportunity to develop and to refine our critical dialectical pluralist FGD process. Specifically, we have served as research-facilitators, whereas the research methodologists whom we teach served as research-facilitators. These research-facilitators addressed the following two sets of social justice-based research questions that they co-constructed:

1). What are the challenges in teaching research methodology at your African institution? What are possible solutions to these challenges?

2). What are the challenges in supervising post-graduate students at your African institution? What are possible solutions to these challenges?

We divided the 25 or so participants into four FGD teams of six or seven participants. Each of these FGD teams simultaneously undergo the stages that we outlined earlier. We have been able to witness the firsthand the power of critical dialectical pluralist FGDs. In fact, by the end of our 2-week course/workshop, the research-facilitators typically have undergone nine of the 10 stages of the critical dialectical pluralist FGD process.

We contend that critical dialectical pluralism FGDs are flexible because they can be conducted within the quantitative research tradition, the qualitative research tradition, or the mixed research tradition. However, it is typically optimal when conducted using mixed research techniques. Moreover, critical dialectical pluralism FGDs, by its very nature, has great potential to enable participants to find solutions to their own problems, thereby moving toward social justice, as they-and not the researchers-define it.

\section{References}

Baez, B. (2007). Thinking critically about the 'critical' quantitative research as social critique. In F. K. Stage (Ed.), Using quantitative data to answer critical questions (pp. 17-23). San Francisco, CA: Jossey-Bass. http://dx.doi.org/10.1002/ir.201

Berelson, B. (1952). Content analysis in communicative research. New York, NY: Free Press.

Butler, S. (1996). Child protection or professional self-preservation by the baby nurses? Public health nurses and child protection in Ireland. Social Science and Medicine, 43, 303-314. http://dx.doi.org/10.1016/0277-9536(95)00378-9

Cho, J., \& Trent, A. (2006). Validity in qualitative research. Qualitative Research, 6, 319-340. http://dx.doi.org/10.1177/1468794106065006

Collins, K. M. T., Onwuegbuzie, A. J., Johnson, R. B., \& Frels, R. K. (2013). Practice note: Using debriefing interviews to promote authenticity and transparency in mixed research. International Journal of Multiple Research Approaches, 7, 271-283. http://dx.doi.org/10.5172/mra.2013.7.2.271

Delgado, R., \& Stefancic, J. (2012). Critical race theory: An introduction (2nd ed.). New York, NY: New York University Press.

Denham, M. A., \& Onwuegbuzie, A. J. (2013). Beyond words: Using nonverbal 
communication data in research to enhance thick description and interpretation. International Journal of Qualitative Methods, 12, 670-696.

DeRocher, J. E., Miron, M. S., Patten, S. M., \& Pratt, C. C. (1973). The counting of words: A review of the history, techniques and theory of word counts with annotated bibliography. New York, NY: Syracuse University Research Corporation. Retrieved from ERIC database. (ED098814).

Duggleby, W. (2005). What about focus group interaction data? Qualitative Health Research, 15, 832-840. http://dx.doi.org/10.1177/1049732304273916

Glaser, B. G. (1965). The constant comparative method of qualitative analysis. Social Problems, 12, 436-445. http://dx.doi.org/10.1525/sp.1965.12.4.03a00070

Hesse-Biber, S. N. (2010). Feminist approaches to mixed methods research: Linking theory and praxis. In A. Tashakkori \& C. Teddlie (Eds.), Sage handbook of mixed methods in social \& behavioral research (2nd ed., pp. 169-192). Thousand Oaks, CA: Sage.

Johnson, R. B., \& Christensen, L. (2013). Educational research: Quantitative, qualitative, and mixed approaches (5th ed.). Thousand Oaks, CA: Sage.

Krueger, R. A. (1994). Focus groups: A practical guide for applied research (2nd ed.). Thousand Oaks, CA: Sage. http://dx.doi.org/10.1037/10518-189

Krueger, R. A. (2000). Focus groups: A practical guide for applied research (3rd ed.). Thousand Oaks, CA: Sage. http://dx.doi.org/10.1037/10518-189

Krueger, R. A., \& Casey, M. A. (2000). Focus groups: A practical guide for applied researchers (3rd ed.). Thousand Oaks, Sage.

Leech, N. L., \& Onwuegbuzie, A. J. (2007). An array of qualitative data analysis tools: A call for qualitative data analysis triangulation. School Psychology Quarterly, 22, 557-584. http://dx.doi.org/10.1037/1045-3830.22.4.557

Manning, K. (1997). Authenticity in constructivist inquiry: Methodological considerations without prescription. Qualitative Inquiry, 3, 93-115. http://dx.doi.org/10.1177/107780049700300105

Maxwell, J. A. (1992). Understanding and validity in qualitative research. Harvard Educational Review, 62, 279-299. http://dx.doi.org/10.17763/haer.62.3.8323320856251826

Mertens, D. (2003). Mixed methods and the politics of human research: The transformative-emancipatory perspective. In A. Tashakkori \& C. Teddlie (Eds.), Handbook of mixed methods in social and behavioral research (pp. 135-164). Thousand Oaks, CA: Sage.

Mertens, D. M. (2007). Transformative paradigm: Mixed methods and social justice. Journal of Mixed Methods Research, 1, 212-225. http://dx.doi.org/10.1177/1558689807302811

Mertens, D. M. (2010). Philosophy in mixed methods teaching: The transformative paradigm as illustration. International Journal of Multiple Research Approaches, 4, 9-18. 
http://dx.doi.org/10.5172/mra.2010.4.1.009

Morgan, D. L. (1988). Focus groups as qualitative research. Newbury Park, CA: Sage.

Morgan, D. L. (1997). Focus groups as qualitative research (2nd ed.). Qualitative Research Methods Series 16. Thousand Oaks, CA: Sage.

Morgan, D. L. (2008). Focus groups. In L. M. Given (Ed.), The Sage encyclopedia of qualitative methods (Vol. 1, pp. 352-354). Thousand Oaks, CA: Sage. http://dx.doi.org/10.4135/9781412963909.n178

Morrow, R. A., \& Brown, D. D. (1994). Critical theory and methodology (Contemporary Social Theory). Thousand Oaks, CA: Sage.

Nelson, J. A., Onwuegbuzie, A. J., Wines, L. A., \& Frels, R. K. (2013). The therapeutic interview process in qualitative research studies. The Qualitative Report, 18(79), 1-17. Retrieved from http://www.nova.edu/ssss/QR/QR18/nelson79.pdf

Onwuegbuzie, A. J. (2012). Introduction: Putting the mixed back into quantitative and qualitative research in educational research and beyond: Moving towards the radical middle. International Journal of Multiple Research Approaches, 6, 192-219. http://dx.doi.org/10.5172/mra.2012.6.3.192

Onwuegbuzie, A. J., \& Byers, V. T. (2014). An exemplar for combining the collection, analysis, and interpretations of verbal and nonverbal data in qualitative research. International Journal of Education, 4(1), 183-246. http://dx.doi.org/10.5296/ije.v6i1.4399

Onwuegbuzie, A. J., \& Collins, K. M. T. (2007). A typology of mixed methods sampling designs in social science research. The Qualitative Report, 12, 281-316. Retrieved from http://www.nova.edu/ssss/QR/QR12-2/onwuegbuzie2.pdf

Onwuegbuzie, A. J., \& Combs, J. P. (2010). Emergent data analysis techniques in mixed methods research: A synthesis. In A. Tashakkori \& C. Teddlie (Eds.), Sage Handbook of mixed methods in social and behavioral research (2nd ed., pp. 397-430). Thousand Oaks, CA: Sage.

Onwuegbuzie, A. J., \& Frels, R. K. (2013). Introduction: Toward a new research philosophy for addressing social justice issues: Critical dialectical pluralism 1.0. International Journal of Multiple Research Approaches, 7, 9-26. http://dx.doi.org/10.5172/mra.2013.7.1.9

Onwuegbuzie, A. J., \& Hitchcock, J. H. (2015). Advanced mixed analysis approaches. In S. N. Hesse-Biber \& R. B. Johnson (Eds.), Oxford handbook of multiple and mixed methods research (pp. 275-295). New York, NY: Oxford University Press.

Onwuegbuzie, A. J., \& Leech, N. L. (2006). Linking research questions to mixed methods data analysis procedures. The Qualitative Report, 11, 474-498. Retrieved from http://www.nova.edu/ssss/QR/QR11-3/Onwuegbuzie.pdf

Onwuegbuzie, A. J., \& Tashakkori, A. (2015). Utilizing mixed research and evaluation methodology in peace psychology and beyond. In D. Bretherton \& S. F. Law (Eds.), 


\section{Macrothink}

Methodologies in peace psychology: Peace research by peaceful means (pp. 115-137). New York, NY: Springer. http://dx.doi.org/10.1007/978-3-319-18395-4_6

Onwuegbuzie, A. J., Dickinson, W. B., Leech, N. L., \& Zoran, A. G. (2009). Toward more rigor in focus group research: A new framework for collecting and analyzing focus group data. International Journal of Qualitative Methods, 8(3), 1-21.

Onwuegbuzie, A. J., Dickinson, W. B., Leech, N. L., \& Zoran, A. G. (2010). Toward more rigor in focus group research in stress and coping and beyond: A new mixed research framework for collecting and analyzing focus group data. In G. S. Gates, W. H. Gmelch, \& M. Wolverton (Series Eds.); K. M. T. Collins, A. J. Onwuegbuzie, \& Q. G. Jiao (Vol. Eds.), Toward a broader understanding of stress and coping: Mixed methods approaches (pp. 243-285). The Research on Stress and Coping in Education Series (Vol. 5). Charlotte, NC: Information Age Publishing.

Onwuegbuzie, A. J., Dickinson, W. B., Leech, N. L., \& Zoran, A. G. (2011). Un marco cualitativo para la recolección y análisis de datos en la investigación basada en grupos focales. Paradigmas, 3(1), 127-157.

Peters, D. A. (1993). Improving quality requires consumer input: Using focus groups. Journal of Nursing Care Quality, 7, 34-41. http://dx.doi.org/10.1097/00001786-199301000-00006

Plano Clark, V. L., \& Badiee, M. (2010). Research questions in mixed methods research. In A. Tashakkori \& C. Teddlie (Eds.), Handbook of mixed methods in social and behavioral research (2nd ed., pp. 275-304). Thousand Oaks, CA: Sage.

Ragin, C. C. (1987). The comparative method: Moving beyond qualitative and quantitative strategies. Berkeley, CA: University of California Press.

Ragin, C. C. (1989). The logic of the comparative method and the algebra of logic. Journal of Quantitative Anthropology, 1, 373-398.

Ragin, C. C. (1994). Introduction to qualitative comparative analysis. In T. Janoski \& A. M. Hicks (Eds.), The comparative political economy of the Welfare State: New methodologies and approaches (pp. 299-319). New York, NY: Cambridge University Press. http://dx.doi.org/10.1017/CBO9781139174053.013

Ragin, C. C. (2008). Redesigning social inquiry: Fuzzy sets and beyond. Chicago, IL: The University of Chicago Press. http://dx.doi.org/10.7208/chicago/9780226702797.001.0001

Robb, M. P., Maclagan, M. A., \& Chen, Y. (2004). Speaking rates of American and New Zealand varieties of English. Clinical Linguistics \& Phonetics, 18(1), 1-15. http://dx.doi.org/10.1080/0269920031000105336

Sandelowski, M. (2008). Theoretical saturation. In L. M. Given (Ed.), The Sage encyclopedia of qualitative methods (Vol. 1, pp. 875-876). Thousand Oaks, CA: Sage. http://dx.doi.org/10.4135/9781412963909.n456

Saumure, K., \& Given, L. M. (2008). Data saturation. In L. M. Given (Ed.), The Sage 


\section{Macrothink}

Journal of Educational Issues

ISSN 2377-2263

2015, Vol. 1, No. 2

encyclopedia of qualitative methods (Vol. 1, pp. 195-196). Thousand Oaks, CA: Sage. http://dx.doi.org/10.4135/9781412963909.n99

Smith, J. A. (1996a). Beyond the divide between cognition and discourse: using interpretative phenomenological analysis in health psychology. Psychology \& Health, 11, 261-271. http://dx.doi.org/10.1080/08870449608400256

Smith, J. A. (1996b). Evaluating the contribution of interpretative phenomenological analysis. Health Psychology Review, 5, 9-27. http://dx.doi.org/10.1080/17437199.2010.510659

Stage, F. K. (2007). Moving from probabilities to possibilities: Tasks for quantitative criticalists. In F. K. Stage (Ed.), Using quantitative data to answer critical questions (pp. 95-100). San Francisco, CA: Jossey-Bass. http://dx.doi.org/10.1002/ir.207

Teranishi, R. T. (2007). Race, ethnicity, and higher education policy: The use of critical quantitative research. In F. K. Stage (Ed.), Using quantitative data to answer critical questions (pp. 37-49). San Francisco, CA: Jossey-Bass. http://dx.doi.org/10.1002/ir.203

Thomas, J. (1993). Doing critical ethnography. Qualitative research methods (Vol. 26). London, England: Sage. http://dx.doi.org/10.4135/9781412983945

Vaughn, S., Schumm, J. S., \& Sinagub, J. (1996). Focus group interviews in education and psychology. Thousand Oaks, CA: Sage. 


\section{Appendix}

Appendix 1. Purposive sampling schemes for FGDs

\begin{tabular}{ll}
\hline Sampling Scheme & Description \\
\hline Random Sampling Scheme: & $\begin{array}{l}\text { Choosing individuals for FGDs from a sampling frame (i.e., desired } \\
\text { population) such that every individual in the sampling frame has an equal } \\
\text { Simple }\end{array}$ \\
and independent chance of being selected for the study. \\
Choosing individuals for FGDs from a sampling frame wherein the \\
sampling frame is divided into sub-sections comprising groups that are \\
relatively homogeneous with respect to one or more characteristics and a \\
random sample from each strata is selected. \\
Choosing individuals for FGDs by selecting intact groups that represent \\
clusters of individuals rather than choosing individuals one at a time. \\
Choosing individuals for FGDs from a list by selecting every $k t h$ sampling \\
frame member, where $k$ typifies the population divided by the preferred \\
sample size.
\end{tabular}

Purposive Sampling Scheme:

Convenience

Choosing individuals for FGDs who are conveniently available and willing to participate in the study.

Maximum Variation

Choosing individuals for FGDs to maximize the range of perspectives in each FGD.

Homogeneous

Choosing individuals for FGDs based on similar or specific characteristics.

Criterion

Choosing individuals for FGDs because they represent one or more criteria.

Typical

Choosing individuals for FGDs because they represent average or normal cases.

Intensity

Choosing individuals for FGDs because their experiences relative to the phenomena of interest are viewed as being intense but not extreme.

Critical Case

Choosing individuals for FGDs based on specific characteristic(s) because their inclusion provides researcher with compelling insight about a phenomenon of interest.

Extreme Case

Choosing individuals for FGDs because they represent outlying cases and conducting comparative analyses. 


\author{
Quota \\ Theory-Based \\ Confirming/Disconfirming \\ Snowball/Network/Chain \\ Opportunistic
}

Politically Important Case

Random Purposeful

Stratified Purposeful

Mixed Purposeful

Multi-Stage Purposeful Random

Multi-Stage Purposeful
Researcher identifies desired characteristics and quotas of individuals for FGDs.

Choosing individuals for FGDs because their inclusion helps the researcher to develop a theory.

Choosing individuals for FGDs to verify or to contradict previous results.

Participants are asked to recruit individuals to join the FGDs.

Choosing individuals for FGDs based on specific characteristics (i.e., typical, negative, or extreme) to capitalize on developing events occurring during data collection.

Choosing individuals for FGDs based on their political connection to the phenomena of interest.

Choosing individuals for FGDs randomly from the sampling frame and randomly choosing a desired number of individuals to participate in the study.

Sampling frame is divided into strata to obtain relatively homogeneous sub-groups and a purposeful sample is selected for the FGDs from each strata.

Choosing more than one sampling strategy to select individuals for FGDs and comparing the results emerging from the two or more samples.

Choosing individuals for FGDs in two or more stages. The first stage is random selection and the following stages are purposive selection of participants.

Choosing individuals for FGDs in two or more stages in which all stages reflect purposive sampling of participants.

Note. Adapted from "A typology of mixed methods sampling designs in social science research," by A. J. Onwuegbuzie and K. M. T. Collins, 2007, The Qualitative Report, 12, pp. 285-287. Copyright 2007 by Anthony J. Onwuegbuzie, Kathleen M. T. Collins, and Nova Southeastern University.

\section{Copyright Disclaimer}

Copyright for this article is retained by the author(s), with first publication rights granted to the journal.

This is an open-access article distributed under the terms and conditions of the Creative Commons Attribution license (http://creativecommons.org/licenses/by/3.0/). 